\title{
PEMBAHARUAN SISTEM KUPVA BB SEBAGAI UPAYA PENCEGAHAN DAN PEMBERANTASAN TINDAK PIDANA PENCUCI UANG
}

\author{
Alvian Dwiangga Jaya*, Ersya Dwi Nurifanti \\ Universitas Pembangunan Nasional "Veteran" Jawa Timur \\ *Correspondent Email: alviandwianggawijaya@gmail.com
}

Naskah diterima: 29/10/2021, Revisi: 15/11/2021, Disetujui: 31/12/2021

\begin{abstract}
Abstrak
Pertumbuhan perekonomian, pariwisata dan infrastruktur Indonesia yang masif menyebabkan banyaknya wisatawan asing berkunjung ke Indonesia, hal ini menimbulka suatu kebutuhan untuk disediakannya fasilitas penukaran valuta asing atau money changer. Namun, pada implementasinya money changer ternyata menjadi sarana Tindak Kejahatan Pencucian Uang. Dalam hal ini pemerintah sebenarnya telah menjerat pelaku TPPU tersebut dalam Pasal 3 UU Nomor 8 Tahun 2010 tentang Pencegahan dan Pemberantasan Tindak Pidana Pencucian Uang. Namun, masih ditemukan banyak kelemahan dalam sistem pengawasan dan penerapan sistem anti money laundering dalam mekanisme transaksi money changer tersebut. Penelitian ini bertujuan untuk menjawab problematika money changer saat ini dengan mengkaji BSPI 2025 terhadap pemberantasan TPPU yang terjadi di Indonesia. Penelitian ini menggunakan metode penelitian normatif dengan menganalisis aspek hukum dan melakukan penelusuran bahan kepustakaan. Penegakan hukum dan pengawasan yang ada saat ini belum mampu menjawab persoalan KUPVA BB dalam TPPU baik secara preventif maupun represif karena masih tingginya angka TPPU dalam KUPVA BB saat ini. BSPI 2025 hadir sebagai solusi untuk menjawab tantangan di era digital khususnya dalam hal ini adalah untuk penanganan masalah KUPVA BB. Kelemahan dalam sistem KUPVA BB sebelum adanya SPI 2025 ini adalah mekanisme transaksi dan pengawasan pemerintah. BI melalui BSPI 2025, akan membentuk sistem yang memuat struktur, pendelegasian pengaturan, dan pembaharuan mekanisme transaksi, hal ini dapat dinilai efektif dalam menangani KUPVA $B B$ dalam TPPU.
\end{abstract}

Kata Kunci : BSPI 2025; Money Changer; Money Laundering; Valuta Asing

\section{PENDAHULUAN}

1. Latar Belakang

How to cite:

Jaya, A., \& Nurifanti, E. (2021). Pembaharuan Sistem KUPVA BB Sebagai Upaya Pencegahan dan Pemberantasan Tindak Pidana Pencuci Uang. Ikatan Penulis Mahasiswa Hukum Indonesia Law Journal, 1(2).

Diterbitkan oleh:

Ikatan Penulis Mahasiswa Hukum Indonesia

IPMHI Law Journal

${ }^{\circ} 2021$ Author 
Indonesia mengalami pertumbuhan perekonomian yang masif dengan didukung oleh upaya-upaya penjagaan stabilitas keamanan nasional, hal ini membuat banyak investor-investor internasional, tertarik untuk menginvestasikan uangnya di Indonesia. Dengan adanya investor-investor yang menanamkan modalnya di Indonesia, membuat banyak perkembangan di berbagai sektor dalam negeri yang secara tidak langsung menimbulkan kemajuan di berbagai bidang, seperti dalam bidang pariwisata yang mana telah membuat banyak wisatawan asing tertarik untuk berkunjung ke Indonesia. Banyaknya wisatawan asing yang berkunjung ini, menyebabkan timbulnya suatu kebutuhan untuk disediakannya fasilitas penukaran valuta asing (currency exchange) atau money changer.

Money changer di Indonesia pada awalnya hanya terdapat pada perbankan. Namun, dengan berkembangnya sistem perekonomian dan kebutuhan pada penukaran valuta asing dalam bentuk uang tunai, lalu kebutuhan untuk penukaran uang rupiah ke berbagai macam valuta asing, pemerintah melalui Bank Indonesia telah membuat dan menetapkan sebuah peraturan untuk diadakannya lembaga Kegiatan Usaha Penukaran Valuta Asing Bukan Bank atau yang lebih sering disebut sebagai KUPVA BB. KUPVA BB memiliki makna yang sama dengan money changer, yaitu lembaga untuk menukarkan valuta asing, namun terdapat dua versi, yaitu money changer perbankan dan money changer non-bank. Persebaran KUPVA BB di Indonesia sendiri, paling banyak ada di daerah-daerah yang sering dikunjungi oleh turis-turis asing, seperti di Bali, Jakarta, Batam, Bandung, Yogyakarta dan Surabaya. KUPVA adalah kegiatan jual dan beli Uang Kertas Asing (UKA), serta pembelian Cek Pelawat. Setiap tahunnya, tercatat pertumbuhan KUPVA BB baru di Indonesia terus meningkat. Data di Tahun 2020, telah ada 1160 kantor pusat KUPVA BB serta 995 kantor cabangnya.

Tingginya pertumbuhan KUPVA BB di Indonesia masih memiliki kekurangan. Kekurangan tersebut adalah ada pada regulasi mengenai KUPVA BB atau money changer di Indonesia sendiri, masih belum diatur dalam peraturan perundang-undangan yang ada dalam Undang-Undang No 12 Tahun 2011 tentang Pembentukkan Peraturan Perundang-Undangan. Pengaturan mengenai KUPVA BB di Indonesia hanya berdasarkan pada Peraturan Bank Indonesia Nomor 18/20/PBI/2016 Tentang Kegiatan Usaha Penukaran Valuta Asing Bukan Bank, kemudian untuk mengenai teknisnya diatur pada Surat Edaran Bank Indonesia No.18/42/DKSP tentang Kegiatan Usaha Penukaran Valuta Asing Bukan Bank. Hal ini merupakan suatu kelemahan atau masalah dalam sistem pengaturan KUPVA itu sendiri dan penegakan hukumnya di Indonesia.

Sebelumnya, Indonesia pun sudah menerapkan e-Court bagi perkara perdata. Akhirnya, pada tahun 2020 MA bersama Kejaksaan Agung RI serta Kementerian Hukum dan HAM telah membuat perjanjian kerja sama untuk melakukan persidangan melalui teleconference termasuk perkara pidana.

PPPATK atau Pusat Pelaporan dan Analis Keuangan, menyampaikan bahwa dalam kurun waktu 18 tahun, terhitung sejak bulan Januari 2003 hingga Januari 2021, telah tercatat bahwa ada 578.134 Laporan Transaksi Keuangan Mencurigakan (LKTM). Bahkan, peningkatan pelaporan ini sebesar 54,3\%, terjadi sejak disahkannya Undang-Undang Nomor 8 Tahun 2010 tentang Pencegahan dan Pemberantasan Tindak Pidana Pencucian Uang.

KUPVA BB atau money changer ternyata tidak hanya dipakai untuk menukarkan atau jual beli valas. Kupva BB juga kerap menjadi sarana beragam tindak pidana. Badan Narkotika Nasional (BNN) mencatat ada indikasi praktik 
Tindak Pidana Pencucian Uang (TPPU) yang berkaitan dengan narkotika melalui sektor jasa keuangan. Sejauh ini, BNN baru mau memberikan sedikit informasi khususnya mengenai penyalahgunaan Kupva BB sebagai wadah melakukan TPPU yang nilainya cukup fantastis, yakni mencapai 3,6 Triliun. Total nilai tersebut khusus untuk Kupva BB yang tidak memiliki izin dari otoritas Bank Indonesia (BI). Bahkan di kota Surabaya, Badan Narkotika Nasional (BNN) mengungkap kasus pencucian uang penjualan narkotika senilai Rp 24 miliar, Kepala BNN Komjen Pol Heru Winarko mengungkapan modus yang digunakan oleh tersangka untuk melakukan pencucian uang. Salah satunya dengan menggunakan perusahaan money changer dan perusahaan di bidang emas dan tembaga.

Tingginya kasus Pencucian uang tersebut diakibatkan oleh Tindak Pidana asal (predicate crime) seperti, tindak pidana korupsi, transaksi narkoba, tindak pidana penggelapan pajak dan perjudian online. Berbagai macam tindak pidana ini tidak hanya melibatkan KUPVA BB tidak berizin, namun juga yang berizin. Modus operandi tindak pidana narkotika melalui KUPVA BB memiliki pola transaksinya adalah dengan bandar narkotika menggunakan KUPVA BB tidak berizin, kemudian KUPVA BB ilegal tersebut bekerja sama dengan KUPVA BB berizin untuk mencairkan dananya. Adapun modus lainnya adalah menggunakan model dengan membentuk perusahaan baru yang legal namun di dalamnya terjadi operasi tindak pidana, perusahaan dengan modus ini dapat disebut sebagai shell company. Melalui perusahaan tersebut dijalankan transaksi yang dibuat seolah-olah ada kegiatan transaksi legal. Padahal, pelaku usaha money changer ilegal dapat dijerat dengan UU Nomor 8 Tahun 2010 tentang Pencegahan dan Pemberantasan Tindak Pidana Pencucian Uang. Lebih lanjut, tak cuma pelaku utama pencucian uang, namun pelaku usaha KUPVA BB atau money changer yang tak mengantongi izin dari BI juga dapat dianggap membantu terjadinya kejahatan pengaburan asal usul harta.

Dalam upaya menangani tingginya kasus money changer maka diperlukan tindakan represif maupun preventif terhadap penyimpangan yang terjadi dalam transaksi pada KUPVA BB ini, agar penyimpangan yang terjadi tidak terulang lagi di masa mendatang serta untuk menjamin ketaatan pelaku usaha money changer terhadap peraturan perundang-undangan di bidang perbankan hal ini harus dilakukan mengingat semakin canggihnya berbagai bentuk kejahatan yang mempunyai jaringan internasional dan menggunakan lembaga keuangan khususnya money changer sebagai sasaran dan sarana untuk melakukan TPPU, maka dalam hal ini Bank Indonesia (BI) dituntut harus lebih waspada dalam melakukan pengawasan pada lembaga KUPVA BB tersebut, karena money changer dalam roda perekonomian Indonesia memiliki kontribusi yang cukup besar, pada tahun 2016 tercatat money changer atau KUPVA BB berkontribusi sebesar 8-9\% atau setara dengan Rp 22,59 triliun dari total transaksi Rp 251 triliun.

Dalam hal ini Bank Indonesia juga memiliki sebuah program yang disebut sebagai Blueprint Sistem Pembayaran Indonesia (SPI) 2025 yang memiliki visi untuk menjamin keseimbangan antara inovasi dengan integritas sistem pembayaran, melalui penerapan Anti Pencucian Uang, Pencegahan Pendanaan Terorisme. Dalam sistem tersebut BI, berupaya untuk memaksimalkan mekanisme transaksi yang aman dan bebas money laundering, guna menciptakan Indonesia yang bebas dari tindak pidana pencucian uang, khususnya dalam transaksi KUPVA BB.

\section{Perumusan Masalah}

1. Bagaimana problematika KUPVA BB di Indonesia terhadap TPPU? 
2. Bagaimana penerapan KUPVA BB oleh BSPI 2025 guna mencegah TPPU di Indonesia?

\section{METODE}

Jenis penelitian yang digunakan dalam penelitian ini adalah penelitian yuridis normatif yang digunakan untuk mengkaji peraturan perundangundangan.Berguna untuk keperluan akademis yang digunakan untuk keperluan akademis dan dapat digunakan untuk menyusun karya akademis. Penelitian normatif merupakan penelitian yang dilakukan dengan cara meneliti bahan pustaka atau data sekunder yang terdiri dari bahan hukum primer, bahan hukum sekunder dan bahan hukum tersier. Penelitian Yuridis-normatif tersebut juga merupakan penelitian hukum yang dilakukan dengan cara meneliti bahan pustaka atau data sekunder sebagai bahan dasar untuk diteliti dengan cara mengadakan penelusuran terhadap peraturan-peraturan dan literature-literatur yang berkaitan dengan permasalahan yang diteliti, selanjutnya bahan-bahan tersebut disusun kemudian dikaji dan ditarik kesimpulan mengenai hubungan dengan masalah yang diteliti.

\section{HASIL PENELITIAN DAN PEMBAHASAN}

\section{PROBLEMATIKA KUPVA BB TERHADAP KASUS TPPU DAN} PENEGAKAN HUKUMNYA

Terdapat bentuk usaha dan kegiatan dalam bidang keuangan yang dalam menjalankan usahanya, bisa dikelompokkan dalam suatu sistem keuangan yang dikenal sebagai lembaga keuangan. Lembaga keuangan sendiri, dapat berupa bank maupun non bank yang dapat menyalurkan uang masyarakat secara efektif dan efisien dalam suatu sistem keuangan. Diantara lembaga keuangan non bank tersebut, salah satunya adalah Kegiatan Usaha Penukaran Valuta Asing bukan Bank (KUPVA BB) atau yang lebih sering disebut sebagai Money Changer. Hal ini telah diatur pada Peraturan Bank Indonesia No.18/20/PBI/2016 dan Surat Edaran Bank Indonesia No.18/42/DKSP tentang Kegiatan Usaha Penukaran Valuta Asing Bukan Bank:

Kegiatan money changer tersebut diawasi dan dibina oleh Bank Indonesia (BI) sebagai bank sentral, karena BI memiliki kewajiban untuk memastikan bahwa usaha money changer tersebut tidak merugikan masyarakat, hal ini sesuai dengan PBI 18/20/PBI/2016 Pasal 16, Pasal 17, dan Pasal 18. Maka, setiap penyelenggara KUPVA diwajibkan untuk memperoleh izin dari BI untuk beroperasi. Namun, dalam fakta di lapangan dapat ditemukan banyak penyelenggara KUPVA ilegal yang tersebar di kotakota besar. Pada tahun 2017 terdapat 783 money changer atau KUPVA BB ilegal yang terindikasi melakukan pencucian uang hingga memberikan pendanaan untuk kegiatan terorisme. Namun, tidak menutup kemungkinan bahwa money changer yang telah berizin pun dapat melakukan TPPU. Hal ini dijelaskan oleh Brigjen Polisi Rokhmad Susanto, yang mengatakan bahwa KUPVA BB berizin dan tidak berizin dapat menjadi sarang ragam tindak pidana khusus, seperti TPPU, transaksi narkotika, dan pendanaan terorisme.

Modus operandi tindak pidana pencucian uang melalui money changer ini memiliki pola transaksi yaitu, penyelenggara transfer dana dan KUPVA BB yang tidak berizin menjadi perantara transaksi keuangan dengan sumber dananya yang ilegal (dirty money). Kemudian, lembaga KUPVA BB ilegal tersebut akan menggunakan rekening pribadi yang jumlahnya lebih dari satu 
dengan menggunakan identitas nasabah yang dipalsukan. Lalu, KUPVA BB ilegal tersebut akan menjalin kerja sama dengan KUPVA BB berizin yang akan mencairkan dana dan menukarkannya dengan valas. Modus operandi ini cenderung rumit dan sulit terdeteksi oleh Pusat Pelaporan dan Analisis Transaksi Keuangan (PPATK), Kepabeanan maupun Kepolisian. Sulitnya pendeteksian TPPU ini, karena pelaku menggunakan transaksi tunai. Transaksi tunai ini, hanya membuat penyidik dapat mengetahui siapa penerimanya, namun pengirim atau asal uang tersebut tidak dapat diketahui. Maka dari itu, penggunaan transaksi tunai melalui money changer ini lebih menguntungkan pelaku TPPU tersebut karena bila dilakukan melalui transfer dana melalui lembaga perbankan, akan lebih mudah terdeteksi.

Pola pencucian uang dalam money changer, memiliki beberapa fase, yaitu pada fase placement, layering, dan integration. Pada fase placement atau menempatkan uang tunai hasil kejahatan ke dalam sistem keuangan, dalam hal ini adalah memasukkan uang pada lembaga KUPVA BB. Setelah memasuki sistem keuangan, maka fase berikutnya adalah layering. Fase layering ini adalah fase yang paling penting dan paling rumit, karena pelaku harus mengaburkan atau menyamarkan uang ilegal tersebut melalui berbagai transaksi keuangan agar sulit untuk dideteksi. Fase layering pada KUPVA BB adalah dengan menukarkan uang haram dalam jumlah besar dengan mata uang asing. Lalu terjadilah transaksi antara uang hasil perdagangan narkoba maupun korupsi yang menggunakan mata uang lokal yang kemudian ditukar dengan sejumlah uang bermata uang asing. Lalu, yang terakhir adalah fase integration. Fase ini adalah fase terakhir dalam proses TPPU.

Salah satu kasus money laundering melalui money changer di Indonesia adalah dalam Putusan PN Jakarta Pusat No. 1056/Pid.B/2005/PN.Jkt.Pst, yang mana Ie Mien Sumardi merupakan tersangka yang telah melakukan TPPU di PT. Yan Shama Linque (PT. YSL) dan PT. Dinamis Citra Swakarsa Money Changer (PT. DCS) atas permintaan Lisa Santoso yang merupakan pemegang saham PT Interesia Securitindo untuk membeli valuta asing berupa SGD (Singapore Dollar). Uang tersebut merupakan hasil korupsi dari P.T. Bank Global Internasional Tbk., tersangka terbukti dengan sengaja melakukan TPPU ke tempat penukaran valas secara tidak normal. Modus operandi yang dilakukan oleh tersangka adalah dengan menggunakan KUPVA BB sebagai sarana untuk mengaburkan asal usul harta yang diperoleh melalui tindak pidana (dirty money).

Kasus selanjutnya yang menggunakan money changer sebagai modus operandi TPPU adalah dalam kasus tindak pidana korupsi yang dilakukan oleh Terpidana Dr. Pinangki Sirna Malasari atas kasus suap dengan Terpidana Joko Tjandra yang tercantum pada Putusan Nomor 10/PD.SUS.TPK/2021/PT DKI. Terpidana Pinangki terbukti telah berupaya untuk menyembunyikan asal-usul harta kekayaannya, yang berasal dari hasil tindak pidana korupsi (TIPIKOR), dengan menukarkan USD 337.600 dengan total nilai penukaran menjadi mata uang rupiah sebesar $\mathrm{Rp}$ 4.753.829.000 melalui beberapa lembaga money changer dengan cara menggunakan identitas orang lain. Hasil dari tindakan kriminal tersebut digunakan oleh Terpidana Pinangki untuk membelanjakan keperluan pribadinya.

Kasus selanjutnya adalah penggunaan money changer untuk "membersihkan" dirty money hasil dari penjualan narkotika. Modus operandinya adalah dengan membangun perusahaan legal yang di dalamnya 
seolah-olah terjadi kegiatan normal yang tidak melanggar hukum atau yang sering disebut shell, seperti melakukan transaksi dan importasi. Namun, yang sebenarnya terjadi adalah perusahaan tersebut adalah kedok untuk menutupi kegiatan transaksi narkotika dan menggunakan perusahaan tersebut untuk memalsukan invoice dan importasi. Kemudian, uang dari hasil kegiatan tersebut akan dikirim ke luar negeri, dengan menggunakan banyak rekening bank yang untuk melakukan kegiatan tersebut agar tidak terlalu mencurigakan. uang yang telah dihasilkan tadi akan dipecah-pecah ke beberapa rekening tersebut, lalu uang tersebut akan ditarik tunai dan ditukarkan dengan valas.

Dalam beberapa kasus, KUPVA BB atau money changer memang tidak menjadi pelaku aktif, kebanyakan dari lembaga penukaran valas tersebut tidak mengetahui asal muasal dana customernya, karena dalam transaksinya sering kali lembaga KUPVA BB tersebut tidak menerapkan prinsip know your customer (KYC). Hal ini seringkali dilakukan oleh money changer yang ilegal, karena lembaga tersebut tidak diawasi oleh otoritas yang berwenang, seperti di Indonesia, lembaga money changer berizin diawasi oleh BI, sedangkan money changer ilegal seringkali luput dari pengawasan. Pada tahun 2017, BNN menemukan bahwa terdapat 6 KUPVA BB yang dijadikan sebagai perantara atau perputaran uang hasil bisnis perdagangan narkoba dengan nilai hampir mencapai Rp. 4 Triliun. Penggunaan money changer ini ternyata tidak hanya melibatkan yang ilegal saja, namun dalam penyelidikan polisi, terdapat 2 lembaga money changer legal yang terlibat. Dana hasil dari pertukaran tersebut, akan ditransfer ke luar negeri melalui rekening perbankan. Salah satu kasus transaksi narkoba yang melibatkan money changer sebagai perantaranya adalah dalam kasus jaringan mafia narkoba Candra Halim dan Freddy Budiman.

Kasus selanjutnya adalah praktik pencucian uang dengan penghindaran pajak atau tax avoidance. Praktik ini kerap dilakukan oleh eksportir dan importir yang ingin mengecilkan pajaknya, dengan mengecilkan nilai barangnya, lalu bekerja sama dengan pembeli di luar negeri, kemudian uang hasil transaksi tersebut akan dimasukkan melalui money changer karena mereka juga bisa mengelola pengiriman uang secara langsung. Wajib pajak cenderung menghindari pajak dan dengan sengaja melaksanakan fraud perpajakan dengan melakukan penggelapan laporan keuangan.

TPPU selanjutnya yang terjadi melalui money changer adalah terkait dengan transaksi hasil perjudian. Salah satu kasus yang menggunakan money changer sebagai modus operandi TPPU hasil perjudian pada PT Sinar Bahagia Utama di Batam. Pemilik money changer tersebut, Antony Tandian memanfaatkan money changer untuk menyamarkan hasil perjudian online ilegalnya dengan keuntungan per bulannya mencapai Rp 30 miliar.

Tingginya kasus TPPU pada money chnager seperti yang telah di jelaskan di atas menunjukkan bahwa masih banyak kelemahan pada sistem operasi dan pengawasan pemerintah, khususnya BI selaku lembaga yang berwenang untuk mengawasi KUPVA BB. Money changer sebagai salah satu bagian penting pada roda perekonomian Indonesia, harus memiliki sistem operasi yang bebas dari TPPU. Hal ini ditunjukkan dengan kedudukan money changer yang berkontribusi cukup besar pada valas yaitu dengan rasio 8-9\% atau setara dengan $\mathrm{Rp} 22,59$ triliun dari total transaksi Rp 251 triliun pada 2016. Dengan melihat data tersebut dan dihubungkan dengan tingginya kasus 
TPPU pada money changer, maka tentu saja banyak pihak yang dapat dirugikan atas kasus-kasus tersebut. Khususnya pemerintah.

Dalam penegakannya, Bank Indonesia baik di Kantor Pusat (KP) maupun di Kantor Perwakilan (KPw), telah melakukan pengawasan langsung dan pengawasan tidak langsung terhadap Penyelenggara KUPVA BB. Berdasarkan hasil pengawasan tersebut, sebagian besar Penyelenggara KUPVA BB masih memiliki skor penerapan program Anti Pencucian Uang (APU) dan Pencegahan Pendanaan Terorisme (PPT) dengan predikat kurang baik. Hal ini antara lain disebabkan masih kurangnya pemahaman Penyelenggara KUPVA BB terhadap ketentuan APU dan PPT, ketidakpedulian komisaris dan direksi terhadap penerapan prosedur Customer Due Diligence (CDD)/ Enhance Due Diligence (EDD), Beneficial Owner (BO) dan tingkat kesadaran yang masih rendah dari Penyelenggara KUPVA $\mathrm{BB}$ terhadap manajemen risiko (risk management) penyelenggara KUPVA $\mathrm{BB}$, khususnya risiko yang timbul dari pencucian uang dan pembiayaan terorisme. Selain lemahnya penerapan program APU dan PPT, para penyelenggara KUPVA BB juga masih memiliki kelemahan dalam implementasi ketentuan operasional KUPVA BB antara lain belum sepenuhnya melakukan permintaan dokumen underlying transaksi untuk transaksi penjualan valas kepada nasabah dengan nominal ekuivalen $\$ 25.000$ per orang per bulan.

Dalam penanganannya, Direktur Tindak Pidana Ekonomi Khusus Markas Besar Polisi Republik Indonesia (selanjutnya disingkat POLRI), Agung Setya mengemukakan bahwa pihaknya terus melakukan pemantauan terhadap pelaku usaha money changer, khususnya pelaku money changer ilegal. Pihak kepolisian menilai, pelaku usaha money changer ilegal seringkali dijadikan alat bagi pelaku tindak pidana untuk menyamarkan asal usul hartanya yang didapat dari tindak kejahatan. Kepolisian Republik Indonesia juga bekerja sama dengan Pusat Pelaporan Analisis dan Transaksi Keuangan (selanjutnya disingkat PPATK) dalam melakukan monitoring. Bareskrim terus lakukan pencegahan dan penegakan hukum supaya bisa lebih pantau dan pastikan semua kegiatan (KUPVA BB atau money changer) punya izin (Bank Indonesia). Pelaku usaha money changer ilegal juga dapat dijerat dengan UU Nomor 8 Tahun 2010 tentang Pencegahan dan Pemberantasan Tindak Pidana Pencucian Uang. Lebih lanjut, tak cuma pelaku utama pencucian uang, namun pelaku usaha KUPVA BB atau money changer yang tak mengantongi izin dari BI dapat dianggap membantu terjadinya kejahatan pengaburan asal usul harta. Pasal 3 berbunyi : "Setiap Orang yang menempatkan, mentransfer, mengalihkan, membelanjakan, membayarkan, menghibahkan, menitipkan, membawa ke luar negeri, mengubah bentuk, menukarkan dengan mata uang atau surat berharga atau perbuatan lain atas Harta Kekayaan yang diketahuinya atau patut diduganya merupakan hasil tindak pidana sebagaimana dimaksud dalam Pasal 2 ayat (1) dengan tujuan menyembunyikan atau menyamarkan asal usul Harta Kekayaan dipidana karena tindak pidana Pencucian Uang dengan pidana penjara paling lama 20 (dua puluh) tahun dan denda paling banyak Rp10.000.000.000,00 (sepuluh miliar rupiah)."

Salah satu upaya hukum yang dilakukan untuk mengatasi tindak pidana pencucian uang yaitu dengan Penerapan ketentuan know your customer (KYC) dalam UU TPPU hal ini secara efektif diperlukan baik dalam rangka kehati-hatian bank maupun dalam rangka mendukung upaya penanganan 
tindak pidana pencucian uang. Sedangkan peranan BI untuk pengawasan kepatuhan bank dan non bank dalam menerapkan KYC juga memperoleh landasan hukum dalam UU TPPU karena penerapan KYC merupakan bagian yang tidak terpisahkan dari upaya pencegahan dan pemberantasan pencucian uang secara menyeluruh. Mengingat sebagian besar transaksi keuangan di Indonesia masih didominasi oleh industri perbankan, maka efektifitas penerapan KYC oleh bank akan secara signifikan menentukan keberhasilan upaya penanganan tindak pidana pencucian uang di Indonesia. Dalam Pasal 39 UU TPPU, menetapkan PPATK mempunyai tugas mencegah dan memberantas tindak pidana pencucian uang.

\section{PENERAPAN KUPVA BB OLEH SPI 2025 DALAM MENCEGAH} DAN MEMBERANTAS TPPU

Bank Indonesia mengetahui bahwa banyak terjadi permasalahan dalam pengoperasian KUPVA BB di Indonesia. Ditambah lagi dengan banyaknya terjadi kasus TPPU dalam KUPVA BB, membuat Bank Indonesia, sebagai lembaga yang memiliki kewenangan untuk mengawasi dan membina KUPVA BB harus menemukan jalan keluar agar Indonesia dapat mengimplementasikan transaksi ekonomi yang Anti Pencucian Uang dan Pendanaan Terorisme. Kuatnya peran KUPVA BB dalam menyediakan layanan perdagangan valas, menjadikan BI harus terus berinovasi dalam melakukan pengawasan dan menciptakan sistem transaksi KUPVA BB yang bebas dari money laundering. Tingginya kasus money laundering dalam KUPVA BB disebabkan oleh masih lemahnya pengawasan oleh otoritas BI, serta masih banyaknya KUPVA BB ilegal yang beredar, membuat transaksi ekonomi yang mencurigakan semakin menjamur terhadap money changer tersebut. Bank Indonesia sebagai bank sentral, harus dapat menjaga struktur ekonomi dan keuangan agar pembangunan ekonomi tidak terganggu.

Sesuai dengan visi keempat SPI 2025, yaitu "menjamin keseimbangan antara inovasi dengan perlindungan konsumen, integritas dan stabilitas serta persaingan usaha yang sehat melalui penerapan prinsip Know Your Customer (KYC) dan Anti Pencucian Uang/Pencegahan Pendanaan Terorisme (APU/PPT), kewajiban keterbukaan data/ informasi/bisnis publik, dan penerapan regtech dan suptech dalam kewajiban pelaporan, regulasi dan pengawasan". Melalui soft infrasturcture melalui penguatan regulasi dan enrty policy yang diberikan oleh SPI 2025, KUPVA BB diharapkan dapat lebih adaptif guna mengantisipasi inovasi teknologi keuangan yang sangat masif. Perlunya kerangka pengaturan yang dapat menata ekosistem keuangan yang kokoh guna mendukung inklusi ekonomi dan keuangan, adanya struktur baru di industri pembayaran nasional, dalam hal ini adalah money changer, akan dibangun sebuah integrasi transaksi yang akan diperkuat dengan pemenuhan sisem know your customer (KYC) untuk mencegah terjadinya money laundering dengan penyelarasan dinamika era digital. Integritas transaksi pada pasar valuta asing (valas) akan diperkuat dengan transparansi transaksi yang dapat mendorong terwujudnya pasar valas yang adil, teratur, likuid dan efisien.

Meningkatnya kompleksitas risiko dalam transaksi valas yang dibuktikan dengan berbagai modus operandi TPPU dalam money changer, menuntut BI untuk berinovasi pada pendekatan perizinan, pelaporan, dan pengawasan sistem pembayaran. Hal ini diimplementasikan dengan adanya 
Regtech (Regulatory Technology) dan Suptech (Supervisory Technology) yang merupakan salah satu cara mengantisipasi pelanggaran dengan memanfaatkan teknologi seperti data base, kecerdasan buatan atau artificial intelligent (IA) hingga blockchain. Adanya Regtech dan Suptech dalam SPI 2025, dapat meningkatkan efektivitas dan efisiensi perizinan, pelaporan, dan pengawasan. Baik Regtech dan Suptech memanfaatkan data digital dalam mensubtitusi cara kerja lama, struktur organisasi dan teknologi informasi dan alat analisis untuk memperkuat proses pengambilan keputusan (Toronto Center, 2017). Selain itu, solusi tersebut dapat mengurangi biaya compliance dan dapat memeprkuat efektivitas manajemen risiko.

Lima inisiatif SPI 2025 adalah; Open Banking, Sistem Pembayaran Ritel, Infrastruktur Pasar Keuangan, Data, serta Pengaturan, Perizinan, dan Pengawasan akan dijabarkan pada 23 key deliverables. KUPVA BB sendiri, tergabung pada Sistem Pembayaran Ritel yang merupakan perubahan secara total perilaku agen ekonomi dalam bertransasksi ke arah aktivitas online, yang menuntut dukungan infrastruktur yang mampu memfasilitasi metode pembayaran digital yang serba mobile, cepat aman, dan murah.

Sistem dan mekanisme dalam SPI 2025 mengarah pada modernisasi infrastruktur sistem pembayaran ritel yang lebih efisien dan aman dengan memanfaatkan teknologi. Digitalisasi dalam KUPVA BB sendiri memang sedang dikembangkan dengan diluncurkannya aplikasi SIKUPVA, dengan adanya aplikasi atau fintech tersebut, diharapkan dapat memudahkan dan menjaga keamanan penukaran valas yang dapat dilakukan secara non tunai. Adanya aplikasi tersebut juga dapat membuat pengguna untuk mengakses money changer berizin. Selain aplikasi SIKUPVA yang mendukung transaksi jual beli valas secara non tunai, terdapat Go Valuta yang dapat memungkinkan penukaran valas dilakukan secara non tunai juga, penjual valas akan menukarkan uangnya lewat rekening asal negara dan pedagang dapat menerima dalam bentuk rupiah.

Sistem pembayaran ritel sendiri, membawahi beberapa layanan, yaitu KUPVA BB dan PTD, Teknologi Financial (Fintech), Elektronifikasi, dan Interface Pembayaran Terintegrasi sebagai infrastruktur. Dalam pelaksanaan KUPVA BB atau money changer, nantinya diharapkan dapat menciptakan pola transaksi yang aman serta dapat selalu terpantau oleh BI, karena melalui SPI 2025, perumusan kerangka baru mengenai pengaturan sistem pembayaran dilatarbelakangi oleh adanya perubahan lingkungan strategis terutama dalam menghadapi era digital.

Kelemahan dalam sistem KUPVA BB sebelum adanya SPI 2025 ini adalah, mekanisme transaksinya hanya terbatas dengan transasksi tunai. Hal ini tentu akan memudahkan pelaku TPPU untuk melakukan operasinya, namun dengan dengan adanya digitalisasi dalam mekanisme KUPVA BB yang dapat memanfaatkan QRIS, Interface Payment yang terintegrasi, serta pengembangan Fast Payment (BI-FAST).

Adanya interface pembayaran yang terintegrasi memiliki prinsipnya merupakan platform yang dapat mengintegrasikan seluruh kanal pembayaran yang menggunakan teknologi API untuk dapat melayani transfer dana baik antar bank maupun non-bank secara real-time. Koneksi interface tersebut dengan BI-FAST dan GPN dapat menjadikan berbagai layanan berbasis mobile menjadi lebih murah dan mudah untuk dilakukan. Selain kedua pembaharuan tersebut, terdapat QRIS yang dapt memperluas akseptasi 
pembayaran nontunai nasional secara lebih efisien. Melalui penggunaan satu strandart QR Code, lembaga KUPVA BB atau money changer dapat tidak memerlukan terlalu banyak atau berbagai macam berbagai jenis QR Code.

Pembaharuan-pembaharuan dalam sistem operasi KUPVA BB yang dibuat oleh BI melalui BSPI 2025, akan membentuk sistem pembayaran baru yang akan memuat struktur, pendelegasian pengaturan dan pendektan pengaturan (regulatory approach) yang menjadi dasar bagi penyusunan dan penerbitan regulasi yang akan datang. Maka penataan ulang lembaga sistem pembayaran KUPVA BB dengan pendekatan activity based dan pihak yang dilayani, termasuk mekanisme dan kriteria entry policy sesuai jenis kelembagaan penyelenggara KUPVA BB.

\section{SIMPULAN DAN SARAN}

\section{A. Kesimpulan}

Dari hasil penelitian tersebut dapat disimpulkan bahwa KUPVA BB terhadap TPPU dari tahun ke tahun terjadi kenaikan dalam Tindak pencucian uang melalui KUPVA BB. Aturan tentang KUPVA BB yang sebelumnya diatur dalam Peraturan Bank Indonesia Nomor 18/20/PBI/2016 Tentang Kegiatan Usaha Penukaran Valuta Asing Bukan Bank dapat disempurnakan dengan adanya BPSI 2025 hadir sebagai solusi dari kelemahan yang ada sebelumnya. BPSI 2025 dapat hadir sebagai upaya Preventif dan juga Represif dalam penanganan KUPVA BB terhadap TPPU. Sistem Pembayaran Ritel yang ada dalam BSPI 2025 yang memiliki Regtech dan Suptech menjadikan sistematika transaksi dalam KUPVA BB menjadi lebih efektif dengan adanya Artificial Intelligent, Big Data Analytic, dan sistem pembayaran yang Real-Time. Pengawasan dalam KUPVA BB juga menjadi lebih terintegrasi dengan adanya framework dalam BSPI 2025 yang lebih mengedepankan keteraturan pelaporan, perizinan, dan sistem pengawasan. Sehingga dalam penerapannya KUPVA BB dalam BSPI 2025 akan dapat mencegah dan memberantas TPPU di Indonesia.

Diharapkan BI dengan adanya program BSPI 2025 semakin proaktif dalam mengawasi pelaku usaha money changer, pengawasan terhadap kegiatan pelaku usaha money changer secara komprehensif, baik pengawasan secara langsung maupun secara tidak langsung agar usaha Money Changer dapat terkontrol dengan baik sehingga dapat memanimalisir pelanggaran yang dilakukan oleh pelaku usaha money changer. Bpsi 2025 dapat menjadi jawaban dari persoalan KUPVA BB Terhadap TPPU dengan aturan yuridis yang juga telah menyempurnakan peraturan yang telah ada sebelumnya.

\section{DAFTAR PUSTAKA}

\section{Buku}

Beritasatu.Com. Bank Indonesia Kembangkan Sistem Pembayaran Ritel Real Time. $\quad$ https://www.beritasatu.com/ekonomi/756185/bank-indonesiakembangkan-sistem-pembayaran-ritel-real-time. (Diakses 1 September 2021).

Bank Indonesia. Blueprint Sistem Pembayaran Indonesia 2025 Bank Indonesia: Menavigasi Sistem Pembayaran Nasional Di Era Digital. https://www.bi.go.id/id/publikasi/kajian/Documents/Blueprint-SistemPembayaran-Indonesia-2025.pdf. (Diakses 29 September 2021). 
Eleanora, Fransiska Novita. "TINDAK PIDANA PENCUCIAN UANG". TINDAK PIDANA PENCUCIAN UANG XXVI, no. 2 (2011). https://media.neliti.com/media/publications/12331-ID-tindak-pidanapencucian-uang.pdf. (Diakses 29 September 2021).

Mathilda, S.H, M.H, Fiorida. "TINDAK PIDANA PENCUCIAN UANG DI BIDANG PERBANKAN CRIME OF MONEY LAUNDERING IN BANKING SECTOR". TINDAK PIDANA PENCUCIAN UANG DI BIDANG PERBANKAN CRIME OF MONEY LAUNDERING IN BANKING SECTOR 5, no. 2 (2013). Accessed September 29, 2021.

Media, Kompas. "Begini Modus Tindak Pidana Narkoba Melalui "Money Changer"". KOMPAS.Com. Accessed September 29, 2021. https://money.kompas.com/read/2017/03/29/193226926/begini.modus.tind ak.pidana.narkoba.melalui.money.changer.

"Peran BI Menuju Indonesia 2025: Prahara, Sengsara, Atau Nusantara Jaya?". Peran Bank Indonesia Menuju Indonesia 2025: Prahara, Sengsara, atau Nusantara Jaya? (2021). Accessed September 29, 2021.

PERATURAN BANK INDONESIA NOMOR 18/20/PBI/2016 TENTANG KEGIATAN USAHA PENUKARAN VALUTA ASING BUKAN BANK, 2016.

Rahmayanti, Rima. Ilmy, Rizky Maidan. Mustofa. "Sharf On The Actors Of NonBank Foreign Exchange Business (Kupva Bb) Or Money Changer". Sharf on the actors of non-bank foreign exchange business (kupva bb) or money changer 2, no. 15 (2019): Single page. Accessed September 29, 2021.

Utomo, Deni. "Ini Cara Pelaku Mencuci Uang Penjualan Narkotika Yang Diungkap BNN". Detiknews. Last modified 2021. Accessed September 29, 2021. https://news.detik.com/berita-jawa-timur/d-4143171/ini-cara-pelakumencuci-uang-penjualan-narkotika-yang-diungkap-bnn. 